\title{
Expanding the Magic Circle in Pervasive Casual Play
}

\author{
Sofia Reis \\ CITI and DI, Faculdade de Ciências e Tecnologia, \\ Universidade Nova de Lisboa \\ 2829-516 Caparica, Portugal \\ se.reis@campus.fct.unl.pt
}

\begin{abstract}
Typically, in digital entertainment, the screen is the center of the player's attention. If the real world was part of the gameplay, the player would also pay attention to what is happening around her. That is the case of pervasive games. Our objective is to find ways of making pervasive play available for a large casual audience, but in a way that casual games are not deprived of their intrinsic characteristics. Casual games are easy to play, have simple rules and easy to understand interfaces and the introduction of real world elements must thus not deprive them of these characteristics.
\end{abstract}

Keywords: pervasive games, casual games, interaction.

\section{$1 \quad$ Introduction and Related Work}

Playing is an activity that has been around for a long time. Games happen inside a magic circle, a sacred isolated space that totally immerses the players [1]. Digital games are games that make use of computers, mobiles phones or game consoles and such games suffer, in our view, of the following problem: the screen is the player's primary or even only focus of attention. It would be interesting if, at least during a few moments, digital games could be played without looking at a screen. Pervasive games have already accomplished that objective with the inclusion of real world elements in games. That way, instead of merely looking at a screen, the player also has to concentrate on what is happening around him or her.

A pervasive game is a "genre in which traditional, real-world games are augmented with computing functionality, or, depending on the perspective, purely virtual computer entertainment is brought back to the real world" [2]. Non pervasive games are played at a certain place, during a certain time and with certain people. In a pervasive game the magic circle is expanded spatially, temporally or socially, so pervasive games may be played everywhere, all the time and eventually with everybody [3]. Human Pacman, REXplorer and Heroes of Koskenniska are three examples of pervasive games. Human Pacman is a pervasive game inspired in the Pacman videogame. In this game, a Pacman player runs around in the real world and Ghost players hunt her down [4]. REXplorer is a spell casting game where tourists encounter spirits that are historical figures [5]. Heroes of Koskenniska is another pervasive game aimed at raising environmental awareness among visitors of a biosphere reserve [6]. 
Our research focus is on casual pervasive games because we intend to include real world elements in games in a way that satisfies the requirements of a casual audience. Windows Solitaire, Tetris and Pacman are good examples of well known classic casual games. Casual games are easy in the sense that they have simple rules and simple to understand interfaces that make use of images and symbols, in detriment of long and fastidious text descriptions. In casual games the gameplay should be as obvious as possible. As a casual game usually runs in parallel with the player's other everyday activities the mental engagement necessary to play the game should be low [7]. In order to remain in the casual segment, the introduction of real world elements should not cause the games to become more complicated, else they will not be casual any more.

Merging casual and pervasive games is an ambitious and difficult objective [3]. Some games have already managed to fit both the requirements of casual and pervasive games. In Insectopia, a pervasive casual game, players use their mobile phones to hunt for rare bugs. Bluetooth devices around the player are the sources of the bugs [8]. Blowtooth also explores the detection of other Bluetooth devices to smuggle drugs [9]. Social Heroes is a game where players trade points by tagging each other using Twitter [10]. We intend to pursue the previous researchers' efforts in combining casual and pervasive games and to outline a framework to integrate real world elements in casual games.

\section{Research Goal}

Our objective is to develop ways of integrating real world elements in casual games and thus decrease the focus of the player's attention on the screen and divert that attention to the environment around the player. We, therefore, intend to introduce a pervasive twist in casual games in a way that complies with the following conditions:

- As casual games are easy and simple, the real world elements must thus be integrated in a way that is also easy and simple for the player.

- Casual players are usually not willing to invest in expensive or specialized hardware [11]. So the inclusion of real world elements will make use of functionality already available (or foreseen in the near future) in devices like computers, portable computers or mobile phones.

\section{Results to Date}

There are many real world elements that can be used in a casual game. So far, we have obtained results in what refers to the inclusion of sound, weather and the player's emotions, activities and location in games. For these real world elements we created games that merge naturally with the players' environment so that the magic circle blurs, expands and eventually overlaps with real life.

For the specific case of sound we created a game, The Castle of Count Pat that merges seamlessly with the activities of an educative setting. The game captures 
sound and shows the sound wave or the frequency spectrum, integrated with an animated character, to students in real time. The quieter the students are the higher the score. A video projector, connected to the computer where the game is running, shows the animated character to all students. The classes where the game was tested became quieter [12].

In another game, we created an Imaginary Friend that resorts to the player's emotions, activities and location. The player's physical activities are detected via the mobile phone's accelerometer so that the Imaginary Friend imitates the human friend, walking when the player walks and stopping and looking up when the player stops. The Imaginary Friend is projected on the floor via a pico projector that is attached to the player's backpack shoulder strap. The pico projector is connected to the mobile phone, where the Imaginary Friend's application is running. A significant increase or decrease in the arousal, detected via an electrodermal activity sensor, may indicate a change in the player's emotions. When this happens, the Imaginary Friend asks what the user is feeling and collects an emotion cookie that is stored inside a jar. The previously collected emotions cookies can also be consulted in a map [13].

Finally, in what refers to the weather, the player merely has to look out the window or step outside to check it without needing any sort of equipment, and that makes it a very pervasive, as well as casual, element. In Weather Wizards the player's powers vary according to the current real weather. The better the players adjust the spells in their grimoire to the real weather conditions the greater the chances of winning the duels [14].

All the mentioned games comply with our research objective of merging the real world with games, in a way that is easy for the player, and making use of functionality already available in devices such as computers, portable computers and mobile phones. The Castle of Count Pat only needs a low end computer, a microphone and a video projector to show the output of the game to students [12]. The Imaginary Friend resorts to a mobile phone, to an electrodermal activity sensor and to a pico projector. Electrodermal activity sensors may become widespread equipment in a near future as there are already companies commercializing such equipment $[15,16]$. As for pico projectors, some mobile phones have already an incorporated projector [17]. For now, mobile phones with embedded projectors are not that widespread, but this may well be a possibility worth considering in the future as a way to solve the problems associated with the small size of mobile phones' screens. Finally, Weather Wizards needs only a mobile phone and a connection to the Internet [14].

\section{Contributions of Our Work to Entertainment Computing and Conclusions}

We are now at point in our research where results have already been collected, but where crucial decisions are still left to be made. Real world elements like the sound, the weather and the player's emotions, activities and location have already been addressed during our research but we are still planning to consider the opportunities provided by video and augmented reality. It is our plan to create a common 
conceptual or software framework that integrates all these real world elements. This framework will be a key result of our research as it may be of use to others who are also working towards binding games and reality. Finally, casual games are games for everyone and research done in this area will benefit a large number of persons. Our objective is to find ways of providing pervasive entertainment for a wide audience of causal players. This work was funded by FCT/MCTES (SFRH/BD/61085/2009) and by CITI (CITI/FCT/UNL - 2011-2012 - PEst-OE/EEI/UI0527/2011.

\section{References}

1. Huizinga, J.: Homo Ludens. Beacon Press (1971)

2. Magerkurth, C., Cheok, A.D., Mandryk, R.L., Nilsen, T.: Pervasive games: bringing computer entertainment back to the real world. Comput. Entertain. 3(4) (2005)

3. Montola, M., Stenros, J., Waern, A.: Pervasive Games: Theory and Design. Morgan Kaufmann (2009)

4. Cheok, A.D., Goh, K.H., Liu, W., Farbiz, F., Fong, S.W., Teo, S.L., Li, Y., Yang, X.: Human Pacman: a mobile, wide-area entertainment system based on physical, social, and ubiquitous computing. Personal Ubiquitous Comput. 8, 71-81 (2004)

5. Ballagas, R.A., Kratz, S.G., Borchers, J., Yu, E., Walz, S.P., Fuhr, C.O., Hovestadt, L., Tann, M.: REXplorer: a mobile, pervasive spell-casting game for tourists. In: CHI EA 2007, p. 1929. ACM Press, New York (2007)

6. Laine, T.H., Gimbitskaya, A., Sutinen, E., Choi, J., Yong, K., Lee, C.: Environmental sensor network for a pervasive learning space in a Finnish biosphere reserve. In: Proceedings of the 5th International Conference on Ubiquitous Information Management and Communication, pp. 88:1-88:6. ACM, New York (2011)

7. Kultima, A.: Casual game design values. In: Proceedings of the 13th International MindTrek Conference: Everyday Life in the Ubiquitous Era on - MindTrek 2009, p. 58. ACM Press, New York (2009)

8. Peitz, J., Saarenpää, H., Björk, S.: Insectopia: exploring pervasive games through technology already pervasively available. In: ACE 2007, p. 107. ACM Press, New York (2007)

9. Linehan, C., Kirman, B., Lawson, S., Doughty, M.: Blowtooth: pervasive gaming in unique and challenging environments. In: CHI EA 2010, p. 2695. ACM Press, New York (2010)

10. Simon, A.: Social heroes: games as APIs for social interaction. In: DIMEA 2008, p. 40. ACM Press, New York (2008)

11. Rohrl, D.: 2008-2009 Casual Games White Paper. IGDA (2008)

12. Reis, S., Correia, N.: The Perception of Sound and Its Influence in the Classroom. In: Campos, P., Graham, N., Jorge, J., Nunes, N., Palanque, P., Winckler, M. (eds.) INTERACT 2011, Part I. LNCS, vol. 6946, pp. 609-626. Springer, Heidelberg (2011)

13. Reis, S., Correia, N.: An imaginary friend that connects with the user's emotions. In: ACE 2011, p. 1. ACM Press, New York (2011)

14. Reis, S., Correia, N.: Engaging the Players with the Use of Real-Time Weather Data. In: Proceedings of the 4o Science and Videogames Conference-2011, Portuguese Society for Videogames Science (2011)

15. edaPlux I PLUX, http: / / plux.info/EDA

16. Q Sensor 2.0, http://www. affectiva.com/q-sensor/

17. Seeser laser pico projector, http: / /www. engadget. com/2011/10/15/seeserlaser-pico-projector-is-always-in-focus-powered-by-andro/ 